unaware of its existence until it appeared-a week after my own report.

In other words, I'm afraid, Now!, quite legitimately, "scooped" the Lancet on its own territory on this occasion. Although it verges on pedantry to expect a lay publication like Now! to be as scrupulous as a relatively academic journal such as the $B M F$ in quoting recondite sources, I entirely agree that sources should be quoted. We will always give credit where it is due, and I hope the $B M \mathcal{F}$ will try harder in future to do the same.

DAvid Loshak Science Editor,
Now! Magazine

London EC1

\section{Congenital varicella}

SIR,-It was interesting to read in Professor A P Waterson's article (8 September, p 564) of the relatively few case reports of congenital abnormalities associated with intrauterine varicella infection. Probably more cases have occurred but not reached the literature.

Three cases of varicella have occurred among pregnant patients booked in this clinic since 1977 . In two cases the mothers were affected at 29 and 31 weeks respectively: in both cases the rash and symptoms were mild. No untoward features occurred during the rest of the pregnancies and the infants did not show any clinical signs of infection at birth. Virus was not isolated from the infants unfortunately $\operatorname{IgM}$ assays and complement fixation tests were not performed.

The third patient was affected earlier in pregnancy, the rash, which was extensive, appearing during the 16 th and 17 th weeks. The infection was confirmed both clinically and by complement fixation test. Acute polyhydramnios and pre-eclampsia were additional complications to this pregnancy from the 31 st week. Ultrasonic assessment at this time suggested the presence of a meningocele and a neurogenic bladder. Labour was induced in the 36th week after prolonged hospitalisation and amniocentesis to relieve the polyhydramnios. A live girl was delivered weighing $2 \cdot 4 \mathrm{~kg}$ (15th-20th percentile for gestational dates), and she remained unconscious throughout her life of 36 hours. She was noted to have a dilated left pupil and a large transparent skin defect above the right iliac crest extending towards the lumbar region. A similar lesion was seen in front of the left ear. There was a flaccid paralysis of the left arm.

Necropsy did not reveal any skeletal abnormalities, and the brain convolutions appeared to be normal. The abnormalities present were an atresia of the sigmoid colon at its junction with the rectum an enlarged bladder with a hypertrophic muscle wall, and a vesicourethral fusion defect with the bladder neck exiting into the vagina. The liver was studded on its surface and internally with hard, yellow nodules measuring about $0.5 \mathrm{~mm}$ in diameter. The abdominal surface of the diaphragm showed many similar lesions and histological examination indicated that these were calcified deposits. The lungs, liver, and spleen showed widespread infiltrative lesions consistent with varicella infection when examined microscopically. Clearly this infant had been subjected to extensive systemic viral effects, the remains of which could be detected in many organs. Possibly the suspected "meningocele" was a large bullous eruption which resulted in the skin defect seen at birth.

The effects of varicella on the fetus are variable and the results of pregnancies affected by this virus are awaited with interest by the clinicians involved and with apprehension by the expectant parents. With our present state of knowledge we can only reassure our patients that abnormalities are "unlikely" and hope that time proves us correct. For this reason it is to be hoped that those who have records of similar cases or subsequently encounter them will make the effort to report them and include details of the duration of pregnancy at the time of the eruption, the severity of maternal symptoms, the further progress of the pregnancy, and the presence or absence of obvious effects on the infant. Unfortunately the recording system of the Office of Population, Censuses and Surveys does not correlate congenital abnormalities with probable aetiological factors, so that retrospective analysis at this level is not possible.

Louise Margaret Maternity Hospital,

IAN ALEXANDER Aldershot, Hants

\section{The premature breech}

SIR,-I read with interest the letter by $\mathrm{Mr}$ J P Calvert (28 July, p 274) advocating the use of the classical caesarean section in some cases of the premature breech.

I agree that the transverse lower segment incision for caesarean section in the premature breech can be hazardous owing to possible entrapment of the fetal head. But the classical caesarean section scar may increase the risk of maternal and perinatal morbidity and mortality owing to scar rupture. ${ }^{12}$ Weakening of the scar may occur during involution of the uterus, and increase in intrauterine pressure during Braxton Hicks's contractions may cause rupture in the next pregnancy.

I would therefore also consider the vertical incision in the lower segment as described by De Lee. ${ }^{3}$ It is possible to make this incision if the lower segment has been stretched sufficiently by active labour. The advantage of the De Lee's incision is that it can be easily extended into the upper uterine segment, and this may occasionally be necessary to allow easy delivery of the aftercoming head.

M ST C HOPPER

St Mary's Hospital,

${ }^{1}$ Myerscough, P R, Munro Kerr's Operative Obstetrics, 9th edn, p 515. London, Ballière Tindall, 1977. Dewhurst, C J, fournal of Obstetrics and Gynaec
of the British Commonwealth, 1957, 64, 113. of the British Commonwealth, 1957, 64, 113 . Medical Association, 1919, 73, 91 .

\section{Antenatal prediction of sex}

SIR,-The report by Dr A J Williams (29 September, p 767) and leading article (p 754) on antenatal prediction of sex quite rightly warn of the pitfalls in predicting the phenotypic sex of an infant based on chromosome analysis of cultured aminotic fluid cells.

No mention was made of the use of amniotic fluid steroid measurements to determine the sex of the fetus. Several workers have reported that amniotic fluid concentrations of testosterone are significantly higher during the second trimester of pregnancies associated with a male fetus. ${ }^{1-4}$ Presumably the same would apply to a $46, \mathrm{XY}$ fetus with normal testosterone biosynthesis but end-orgon unresponsiveness to adrogens (testiculer feminization syndrome). Defects in testosterone biosynthesis and XY gonadal dysgenesis would be associated with amniotic fluid testosterone concentrations appropriate for a female fetus.

The case report by $\mathrm{Dr}$ Williams serves to emphasise that parents should be made aware that knowledge of the fetal sex chromosome complement would not necessarily predict correctly the sex of the infant should there be a disorder of sex differentiation present.

I A Hughes

K M LAURENCE

Department of Child Health, Wepartment of Child Health,
Cardiff CF4 4XN

1 Doerner, G, et al, Endokrinologie, 1973, 61, 317

2 Giles, H R, et al, Gynecologic Investigation, 1974, 5, 317 .
${ }^{3}$ Warne, G L, et al, fournal of Clinical Endocrinology and Metabolism, 1977, 44, 934 . Zondek, L H, Zondek, T, and Mansfield, M, British
Medical fournal, 1979, 1, 341 .

\section{Beta-blocker withdrawal syndrome}

SIR,-We are interested by the letter from $\mathrm{Dr}$ $\mathrm{M} \mathrm{J}$ Lewis and his colleagues (8 September, p 606) commenting on our paper about the beta-blocker withdrawal syndrome (11 August, p 366). Many explanations have been offered for the worsening of angina pectoris when the beta-blockers are suddenly withdrawn, including progression of the disease, adaptation to a greater level of physical activity during beta-blockade, etc. Two explanations have been proposed which might involve the sympathetic nervous system directly in a rebound phenomenon-increased release of noradrenaline from adrenergic nerves to the heart and hypersensitivity of the cardiac $\beta$ receptors.

We investigated patients up to four days after sudden cessation of treatment with propranolol to see whether there was increased sympathetic activity analogous to that which occurs after withdrawal of clonidine and other imidazoline-like compounds which have an $\alpha$ receptor agonist action in the central nervous system. During treatment with propranolol there is a moderate increase in plasma noradrenaline, which probably reflects increased activity of the baroreflex consequent on the reduction in the cardiac output. Using a sensitive and specific radioenzymatic assay, we found a smooth decline in the plasma noradrenaline to normal when propranolol was stopped. Nattel et $a l^{1}$, who used a less specific assay for total plasma catecholamines, found a similar pattern, although the time the catecholamines took to fall was slightly longer in their study. Thus it is common ground that there is not a sudden overshoot of sympathetic activity on cessation of treatment with propranolol

The second possibility concerns supersensitivity of cardiac $\beta$-receptors after a long period of competitive receptor blockade. Nattel et $a l^{1}$ used isoprenaline dose-response curves to study this situation and found a moderate increase in response between the fourth and ninth day after withdrawal. We understand from conversations with $\operatorname{Dr} R \mathrm{E}$ Rangno of this group that they have recently shown a similar phenomenon after cessation of treatment with metoprolol, although the period of hypersensitivity was shorter. The observations made by Ross and his colleagues ${ }^{2}$ are consistent with this explanation.

It is, however, important not to overstate the magnitude of the hypersensitivity. On average it amounted to about a twofold shift in the isoprenaline dose-response curve in the study by Nattel et al. One patient showed a fivefold increase in sensitivity to isoprenaline but this was at only one observation point and might have been a random fluctuation. If a twofold increase in receptor sensitivity is 